\title{
Long-term outcomes of a dual-mobility cup and cementless triple-taper femoral stem combination in total hip replacement: a multicenter retrospective analysis
}

Alain Cypres $^{1 *}$ (D) Arnaud Fiquet ${ }^{2}$, Philippe Girardin³ ${ }^{3}$ David Fitch $^{4}$, Philippe Bauchu ${ }^{5}$, Olivier Bonnard ${ }^{6}$, Daniel Noyer ${ }^{7}$ and Christophe Roy ${ }^{8}$

\begin{abstract}
Background: The separate design concepts of dual-mobility cups and triple-taper femoral stems were developed to improve survivorship following total hip replacement (THR) by reducing instability/dislocation and enabling enhanced fixation. Successful outcomes at over two decades have been reported with earlier-generation devices based on these concepts. The current study aimed to provide the first long-term results with a unique pairing of later-generation dual-mobility cup and triple-taper cementless femoral stem after a decade of use in patients undergoing THR.
\end{abstract}

Methods: In this retrospective analysis, records were reviewed for all subjects implanted with this dual-mobility cup/cementless femoral stem combination at three centers between 2002 and 2005. Any subject who had not already had follow-up visit beyond 10 years, was not previously revised, and still living were invited for a single follow-up visit consisting of Merle d'Aubgine Scores, the Western Ontario and McMaster Universities Osteoarthritis (WOMAC) index, and standard radiographs.

Results: There were 244 THRs available for analysis. At a mean follow-up of 11.9 years, the Kaplan-Meier survivorship (endpoint: revision for any reason) was $99.1 \%$ (95\% Cl, 97.6-99.7) for the stem and 95.9\% (95\% Cl, 93.1-97.6) for the cup. Merle d'Aubigne Scores were significantly improved from baseline and WOMAC scores were in the satisfactory range at the final follow-up. Radiographic analysis revealed no cases of stem subsidence, no cases of bone hypertrophy, 1 $(0.4 \%)$ case of bone atrophy, and $3(1.2 \%)$ cases of osteolysis around the stem. No subjects had radiolucent lines greater than $1 \mathrm{~mm}$ in any femoral Gruen zone. Evidence of cup migration was seen in $1(0.4 \%)$ subject and 1 (0.4\%) subject had evidence of osteolysis that was seen in Gruen zones I, II, IV, and V.

Conclusions: This combination of a later-generation dual-mobility cup and cementless triple-taper stem was associated with excellent survivorship and satisfactory functional outcomes at over 10 years follow-up.

Trial registration: ClinicalTrials.gov, NCT02648152. Date of registration: January 6, 2016. Retrospectively registered. Keywords: Total hip replacement, Dual-mobility cup, Triple-taper stem, Survivorship, Outcomes, Polarstem, Polarcup

\footnotetext{
* Correspondence: alain.cypres3@orange.fr; alaincypres3@sfr.fr

${ }^{1}$ Clinique du Renaison, 75 Rue Général Giraud, 42300 Roanne, France

Full list of author information is available at the end of the article
}

(c) The Author(s). 2019 Open Access This article is distributed under the terms of the Creative Commons Attribution 4.0 International License (http://creativecommons.org/licenses/by/4.0/), which permits unrestricted use, distribution, and reproduction in any medium, provided you give appropriate credit to the original author(s) and the source, provide a link to the Creative Commons license, and indicate if changes were made. The Creative Commons Public Domain Dedication waiver (http://creativecommons.org/publicdomain/zero/1.0/) applies to the data made available in this article, unless otherwise stated. 


\section{Introduction}

Successful outcomes are routinely observed for total hip replacement (THR), with data from both case series and joint registries indicating that all-cause survivorship of > $85 \%$ can be achieved 15 years after primary surgery [1]. Nonetheless, there is a continual drive to improve upon these outcomes by addressing the underlying causes of component revision, a major source of which is instability/dislocation [2].

Among the design concepts created to provide increased stability after THR are dual-mobility cups, first introduced in the 1970s by Bousquet and colleagues [3]. Dualmobility cups combine the foundational principles of low friction, which includes a mobile polyethylene liner locked on a femoral head articulating in a smooth metallic acetabular shell. This double articulating bearing with a large head-to-neck ratio results in enhanced joint mobility before the outer edges of the liner impinges against the femoral neck [4]. Early dual-mobility cups proved adept at decreasing dislocation rates, particularly among elderly patients at high risk for this outcome [5]. Similarly encouraging results have been reported with later-generation dual-mobility cups [6-11]. The continued positive safety and performance observed with these designs has extended their use into younger, more active patients [12], as well as the obese [13].

Triple-tapered femoral stems were introduced as a design concept in the 1980s, with a goal of providing enhanced fixation, reduced subsidence, and improved loading of the proximal femoral neck [14, 15]. Cementless triple-tapered femoral stem designs have welldocumented clinical success over two decades of use [16-20].

The current study was undertaken to determine the long-term survivorship and clinical outcomes of a THR combination consisting of newer-generation cementless dual-mobility cup and cementless triple-tapered stem at a minimum of 10 years follow-up. Although both devices build upon established concepts, this represents the first published report of long-term outcomes with this specific combination. It was hypothesized that these components would lead to revision rates beneath the threshold of $5 \%$ at 10 years established by the Orthopaedic Data Evaluation Panel (ODEP) in the UK [21] as a marker of a successful THR.

\section{Materials and methods}

The study was a multicenter retrospective analysis of all the subjects who underwent primary THR with the POLAR System, comprised of a cementless triple-tapered stem (POLARSTEM ${ }^{\mathrm{m} m}$; Smith \& Nephew Orthopaedics AG, Baar, Switzerland) and cementless dual-mobility cup (POLARCUP ${ }^{\mathrm{m}}$; Smith \& Nephew Orthopaedics AG, Baar, Switzerland), at three centers between 2002 and 2005. All non-revised and non-deceased subjects who were at least 18 years old at the time of implantation and that had received the subject dual-mobility cup and femoral stem unilaterally or bilaterally for osteoarthritis, degenerative joint disease, traumatic events, or inflammatory/rheumatoid processes were invited to return for a follow-up visit at a minimum of 10 years after their original surgery. Subjects were not invited back for a visit if they already had a clinic visit beyond 10 years follow-up, had a medical or health condition which could impair their ability or willingness to comply with the study, or if they refused to sign the informed consent document.

The study's primary objective was to evaluate the long-term survivorship for the dual-mobility cup and cementless triple-taper femoral stem after a decade of use following THR. The secondary objective of the study was to assess the safety and effectiveness of this combination in terms of radiographic and clinical performance.

Medical records were accessed and analyzed for subjects that already had the 10-year follow-up, and in case of missing information, subjects were invited for 10-year plus visit. Subjects returning for the minimum 10-year follow-up visit were assessed using the Western Ontario and McMaster Universities Osteoarthritis (WOMAC) index, Merle D'Aubigne Score, standard radiographs, and evaluated for any complications or revisions. Baseline preoperative Merle D'Aubigne Scores were collected from the medical records when available. Subjects who declined to return, or were previously revised, or were deceased had limited data collected from their medical records. This data included gender, age, study device, and any complications or revisions.

\section{Device description}

All subjects received the dual-mobility system with cup size ranging from 43 to $63 \mathrm{~mm}$ (Fig. 1). This system features an acetabular liner conventional or highly crosslinked polyethylene inserts articulating with either ceramicised metal, ceramic, or cobalt chrome femoral heads. Additionally, patients received the cementless femoral stem (Fig. 2), which was lateral in 39 subjects and standard in 205. This stem is a triple-tapered design manufactured from a Ti-6Al-4 $\mathrm{V}$ alloy. It features a $180-\mu \mathrm{m}$ titanium plasma spray that is coated with $50 \mu \mathrm{m}$ of hydroxyapatite. Femoral head size included $22 \mathrm{~mm}$ and $28 \mathrm{~mm}$ and the neck of the stem is mirror-polished with a 12/14 taper. It is shorter than similar triple-taper designs, which may make it easier to use with muscle-sparing surgical techniques.

\section{Statistical considerations}

Descriptive statistics were used to summarize demographics, WOMAC Scores, Merle D'Aubigne Scores, radiographic outcomes, and complications. Kaplan- 


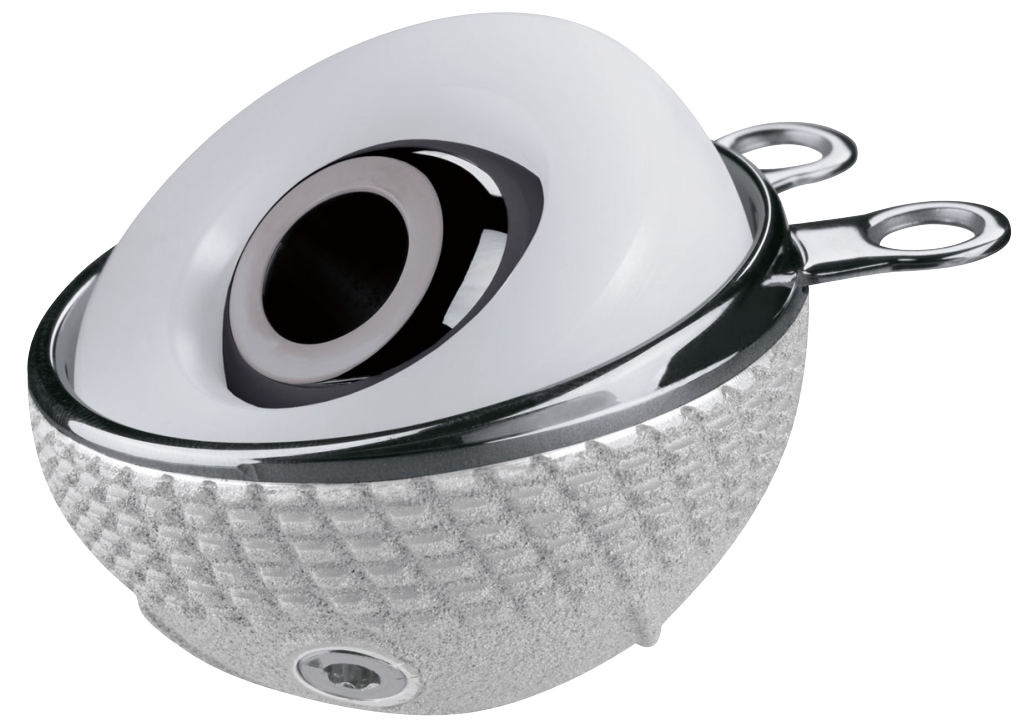

Fig. 1 Dual-mobility Polarcup system

Meier analysis was used to evaluate component survivorship.

\section{Results}

There were 502 THRs implanted during the period of interest that satisfied the inclusion/exclusion criteria, of which 106 refused to return and 152 were deceased, leaving 244 who agreed to return for a follow-up visit (Table 1).

At a mean follow-up time of 11.9 years (range, 10.214.3 years), the Kaplan-Meier survivorship was $99.1 \%$ (95\% CI, 97.6-99.7) with revision of the femoral stem for any reason as the endpoint and 95.9\% (95\% CI, 93.197.6) with revision of the acetabular component for any reason as the endpoint. There were 4 revisions of the femoral stem, all of which were required due to fractures that occurred at 14 days and at 1.1, 24.2, and 61.2 months. There were 17 acetabular component revisions in 15 subjects. In 14 subjects, this was due to aseptic loosening, with revisions occurring at 24.2, 35.4, 80.0, 80.4, 91.3, 96.5, 97.0, 99.4, 112.7, 117.2, 118.7, 121.7, 125.6, and 133.7 months. In the remaining subject, the revision was secondary to a fracture of the femur and occurred at 70.9 months.

Intraoperative and early postoperative complications included $2(0.8 \%)$ superficial infections, 2 (0.8\%) hematomas, 1 deep infection (0.4\%), 1 (0.4\%) femoral fissure, and $1(0.4 \%)$ case of delirium tremens.

Radiographic analysis revealed no cases of stem subsidence, no cases of bone hypertrophy, 1 (0.4\%) case of bone atrophy, and $3(1.2 \%)$ cases of osteolysis around the stem. The case of bone atrophy occurred in a subject with a history of developmental dysplasia and who had multiple acetabular revisions prior to the long-term follow-up visit. No subjects had radiolucent lines greater than $1 \mathrm{~mm}$ in any femoral Gruen zone. Evidence of cup migration was seen in $1(0.4 \%)$ subject and $1(0.4 \%)$ subject had evidence of osteolysis that was seen in Gruen zones I, II, IV, and V.

At the final follow-up, the mean WOMAC total, pain, stiffness, and function scores were 13.9 (range, 0-75), 2.3 (range, 0-14), 1.1 (range, 0-6), and 10.7 (range, 0-56), respectively. Mean Merle D'Aubigne Scores improved from 9.9 (range, 6-15) to 17.0 (range, 10-18).

\section{Discussion}

This group had previously reported low revision for this cohort at 3 years follow-up [22]; however, the current study represents the first long-term analysis of the survivorship of this cup/stem combination. The results confirm that excellent survivorship can be achieved with this dual-mobility cup/cementless triple-taper stem combination after a decade in situ. At nearly 12 years followup, the survivorship for the cup was $95.9 \%$ and for the femoral stem was $99.1 \%$. Therefore, revision rates for both components were beneath the threshold of $5 \%$ revision rate at 10 years used by ODEP [21], which is a widely accepted benchmark for judging the long-term performance of a THR device.

Cementless THR is the most commonly used method of fixation [23]. The key goals for cementless THR are achieving durable primary mechanical stability and osteointegration between implant and bone [24]. The design concepts utilized in this study offer several possible mechanisms for meeting these objectives.

Dual-mobility cups are thought to lower the risk of dislocation by minimizing prosthetic neck impingement and increasing range of motion via the large articulation 


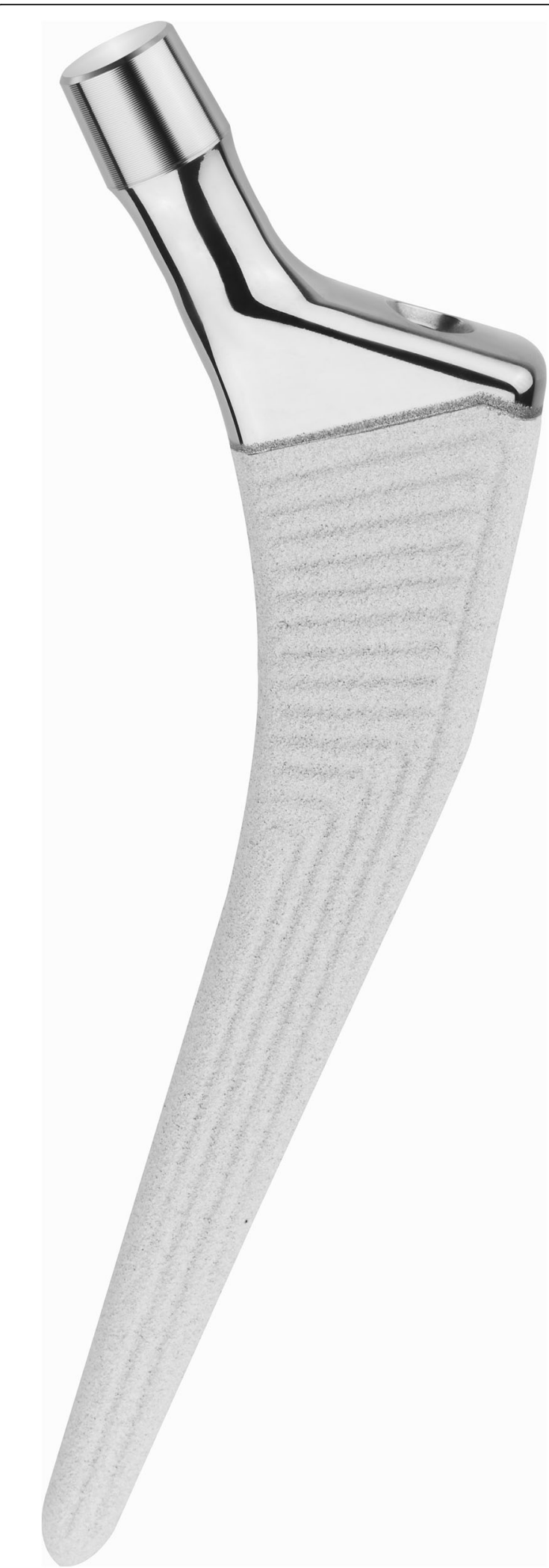

Fig. 2 Side view of the triple-taper Polarstem
Table 1 Demographics for 224 subjects (244 hips) available for the 10-year follow-up visit

\begin{tabular}{ll}
\hline Variable & $N$ \\
\hline Gender & \\
Female & $97(43.3 \%)$ \\
Male & $127(56.7 \%)$ \\
Hip side & \\
Left & $111(45.5 \%)$ \\
Right & $133(54.5 \%)$ \\
Mean subject age at surgery, years (range) & $63.8(29-82)$ \\
Mean body mass index at surgery (range) & $27.6(15.6-41.4)$ \\
Primary diagnosis for surgery & \\
Avascular necrosis & $15(6.1 \%)$ \\
Dysplasia & $8(3.3 \%)$ \\
Femoral neck fracture & $2(0.8 \%)$ \\
Missing & $1(0.4 \%)$ \\
Osteoarthritis & $209(85.7 \%)$ \\
Other & $2(0.8 \%)$ \\
Post-traumatic arthritis & $2(0.8 \%)$ \\
Rheumatoid arthritis & $5(2.0 \%)$ \\
\hline
\end{tabular}

between the insert and metallic shell $[6,25]$. The utility of this design concept is borne out by low dislocation rates reported in several studies this decade with cementless dual-mobility cups [6-11]. In the current study, there were no dislocations in any subjects. The survivorship for the dual-mobility cup used in this study agrees with previously reported midterm outcomes for this system $[26,27]$. In addition, our mean postoperative WOMAC and Merle D'Aubigne scores are comparable to those observed in mid-term follow-up series of cementless dual-mobility cups in primary THR $[6,8,28]$.

There have been concerns raised that dual-mobility cups can contribute to increased polyethylene wear at the site of articulation between its convex surface and the metal surface of the acetabular component, as well as due to impingement of the neck on the rim of the retentive polyethylene [7]. However, this is disputed by simulation studies [7] and retrieval analyses of dualmobility cups $[29,30]$. A recent analysis of 35 explanted liners from dual-mobility cups found the wear to be lower than that reported with equivalent cementless liners [30]. Radiographic analysis from the current study provided no indication that liner wear was an issue after a decade in situ.

The cementless triple-taper femoral stem employed in this analysis is the more extensively studied of the components in this combination, though performance data remain limited to survivorship estimates from a pair of publications and registry reports [31-35]. Assaf et al. reported no revisions of the stem in a 
cohort of 114 THRs followed for 7 years [31], whereas Lee and Evans reported that the subject stem was associated with a cumulative survival rate of $99.1 \%$ at 3 years for over 600 consecutive subjects [32]. The National Joint Registry for England, Wales, Northern Ireland, and the Isle of Man reported 98.9\% (95\% CI, 98.4-99.2) survivorship at 5 years follow-up [33].

There are several potential reasons that account for the reported stability of this femoral stem. The tripletaper stem design concept was created to enhance fixation, reduce subsidence, and improve loading of the proximal femur neck to avoid stress shielding [14, 36]. Triple-taper design has also been noted to result in less periprosthetic bone mineral density loss than straighttype components [14].

Furthermore, the relatively short length of the cementless stem employed here may convey advantages, including greater preservation of bone and optimized proximal load transfer [37]. Compared with standard-length stems, their use has been associated with increased metaphyseal filling [38], decreased intraoperative complications [37, 39], and less thigh pain [39]. The stem also incorporates a titanium plasma spray with hydroxyapatite coating, which may result in improved bone remodeling, subsidence, and migration [40, 41].

Despite being a follow-up of a large cohort of subjects, the study does have some limitations. The study is a retrospective design, which is generally considered to be a lower level of evidence than prospective studies. Another limitation was the use of the Merle d'Aubigne Score, which despite its widespread use, does suffer from well-documented ceiling effects [42-44]. Efforts were made to mitigate these limitations by including the option for a prospective visit beyond 10 years follow-up and including the WOMAC score. Finally, the study was only able to provide follow-up data on $48.6 \%$ (244 out of 502) of THRs among the original cohort. The primary reason for this was that $30.3 \%$ of participants were deceased. Although this undoubtedly impacts the survivorship analysis, it is an unavoidable consequence of conducting follow-up studies of this duration in a relatively older population.

In conclusion, the subject femoral stem was associated with excellent survivorship and satisfactory functional outcomes at over 10 years follow-up. The study shows that this stem design in combination with a dualmobility cup offers a safe and effective treatment of subjects requiring THR due to osteoarthritis over a wide range of subject ages.

\footnotetext{
Abbreviations

ODEP: Orthopaedic Data Evaluation Panel; THR: Total hip replacement; WOMAC: Western Ontario and McMaster Universities Osteoarthritis
}

Acknowledgements

Not applicable.

\section{Authors' contributions}

This article was prepared by DF, in consult with the other authors, who read and approved the final manuscript.

\section{Funding}

Funding for this study was provided by Smith \& Nephew Inc., which contributed to its design and collection, analysis, and interpretation of data. One author (DF) was an employee of Smith \& Nephew Inc. at the time the manuscript was developed.

\section{Availability of data and materials \\ The datasets used and/or analyzed during the current study are available from the corresponding author on reasonable request.}

\section{Ethics approval and consent to participate}

All procedures performed in studies involving human participants were in accordance with the ethical standards of the institutional and/or national research committee and with the 1964 Helsinki declaration and its later amendments or comparable ethical standards.

\section{Consent for publication}

Not applicable.

\section{Competing interests}

$A C, A F, P G, P B, O B, D N$, and $C R$ all hold patents for the study devices mentioned in this manuscript. DF was an employee of Smith \& Nephew at the time this manuscript was developed.

\section{Author details}

${ }^{1}$ Clinique du Renaison, 75 Rue Général Giraud, 42300 Roanne, France. ${ }^{2}$ Infirmerie Protestante, Caluire et Cuire, France. ${ }^{3}$ Hôpital de Montbrison, Montbrison, France. ${ }^{4}$ Smith \& Nephew, Cordova, TN, USA. ${ }^{5}$ GHM les portes du Sud, Venissieux, France. ${ }^{6}$ Clinique du Tonkin, Villeurbanne, France. ${ }^{7}$ Hôpital de Bourgoin-Jallieu, Bourgoin-Jallieu, France. ${ }^{8}$ Group GILES, Chatuzange, France.

Received: 7 July 2019 Accepted: 29 October 2019

Published online: 21 November 2019

\section{References}

1. Evans JT, Evans JP, Walker RW, Blom AW, Whitehouse MR, Sayers A. How long does a hip replacement last? A systematic review and meta-analysis of case series and national registry reports with more than 15 years of followup. Lancet. 2019;393:647-54.

2. Lu Y, Xiao H, Xue F. Causes of and treatment options for dislocation following total hip arthroplasty. Exp Ther Med. 2019;18:1715-22.

3. Bousquet G, Argenson C, Godeneche JL, Cisterne JP, Gazielly DF, Girardin P, Debiesse JL. Recovery after aseptic loosening of cemented total hip arthroplasties with Bousquet's cementless prosthesis. Apropos of 136 cases. Rev Chir Orthop Reparatrice Appar Mot. 1986;72(Suppl 2):70-4.

4. Horriat $\mathrm{S}$, Haddad FS. Dual mobility in hip arthroplasty: what evidence do we need? Bone Joint Res. 2018;7:508-10.

5. Philippot R, Farizon F, Camilleri JP, Boyer B, Derhi G, Bonnan J, Fessy MH, Lecuire F. Survival of cementless dual mobility socket with a mean 17 years follow-up. Rev Chir Orthop Reparatrice Appar Mot. 2008;94:e23-7.

6. Combes A, Migaud H, Girard J, Duhamel A, Fessy MH. Low rate of dislocation of dual-mobility cups in primary total hip arthroplasty. Clin Orthop Relat Res. 2013:471:3891-900.

7. De Martino I, D'Apolito R, Soranoglou VG, Poultsides LA, Sculco PK, Sculco TP. Dislocation following total hip arthroplasty using dual mobility acetabular components: a systematic review. Bone Joint J. 2017;99B(ASuppl1):18-24.

8. Philippot R, Baulot E, Vermorel PH, Genestoux V, Alixant P, Martz P, et al. Outcomes of augmented dual mobility acetabular cups. Surg Technol Int 2019;35:274-9.

9. Philippot R, Meucci JF, Boyer B, Farizon F. Modern dual-mobility cup implanted with an uncemented stem: about 100 cases with 12-year followup. Surg Technol Int. 2013;23:208-12.

10. Prudhon JL, Verdier R, Caton JH. Low friction arthroplasty and dual mobility cup: a new gold standard. Int Orthop. 2017;41:563-71. 
11. Tarasevicius S, Smailys A, Grigaitis K, Robertsson O, Stucinskas J. Short-term outcome after total hip arthroplasty using dual-mobility cup: report from lithuanian arthroplasty register. Int Orthop. 2017;41:595-8.

12. Batailler C, Fary C, Verdier R, Aslanian T, Caton J, Lustig S. The evolution of outcomes and indications for the dual-mobility cup: a systematic review. Int Orthop. 2017:41:645-59.

13. Hernigou P, Trousselier M, Roubineau F, Bouthors C, Flouzat Lachaniette CH. Dual-mobility or constrained liners are more effective than preoperative bariatric surgery in prevention of THA dislocation. Clin Orthop Relat Res. 2016;474:2202-10.

14. Hayashi S, Nishiyama T, Fujishiro T, Kanzaki N, Hashimoto S, Kurosaka M. Periprosthetic bone mineral density with a cementless triple tapered stem is dependent on daily activity. Int Orthop. 2012;36:1137-42.

15. Wroblewski BM, Siney PD, Fleming PA. Triple taper polished cemented stem in total hip arthroplasty: rationale for the design, surgical technique, and 7 years of clinical experience. J Arthroplast. 2001;16(8 Suppl 1):37-41.

16. Vidalain JP. Twenty-year results of the cementless Corail stem. Int Orthop. 2011;35:189-94.

17. Jacquot L, Bonnin MP, Machenaud A, Chouteau J, Saffarini M, Vidalain JP. Clinical and radiographic outcomes at 25-30 years of a hip stem fully coated with hydroxylapatite. J Arthroplast. 2018:33:482-90.

18. Louboutin L, Viste A, Desmarchelier R, Fessy MH. Long-term survivorship of the Corail standard stem. Orthop Traumatol Surg Res. 2017;103:987-92.

19. Xu J, Xie Z, Zhao J, Gao Y, Zhao H, Peng L, Qu Y. Results of a hydroxyapatite-coated femoral stem (Corail) in Chinese: a minimum 10-year follow-up. Springerplus. 2016;5:1983.

20. Carlson SW, Goetz DD, Liu SS, Greiner JJ, Callaghan JJ. Minimum 10-year follow-up of Cementless Total hip Arthroplasty using a contemporary tripletapered titanium stem. J Arthroplast. 2016;31:2231-6.

21. Orthopaedic Data Evaluation Panel (ODEP) Hip Criteria. (2018). http://www. odep.org.uk/Portals/0/Forms/Criteria/ODEP_Criteria_Hips.pdf.

22. Fiquet A, Noyer D. "Polarsystem" dual mobility hip prosthesis and "minimally invasive surgery" (MIS). Interact Surg. 2006;22:1.5.

23. Lehil MS, Bozic KJ. Trends in total hip arthroplasty implant utilization in the United States. J Arthroplast. 2014;29:1915-8.

24. Kim JT, Yoo JJ. Implant Design in Cementless hip Arthroplasty. Hip Pelvis. 2016;28:65-75.

25. Noyer D, Caton JH. Once upon a time.... Dual mobility: history. Int Orthop. 2017:41:611-8.

26. Bauchu P, Bonnard O, Cyprès A, Fiquet A, Girardin P, Noyer D. The dualmobility POLARCUP: first results from a multicenter study. Orthopedics. 2008;31(12 Suppl 2):97-9.

27. Massin P, Orain V, Philippot R, Farizon F, Fessy MH. Fixation failures of dual mobility cups: a mid-term study of 2601 hip replacements. Clin Orthop Relat Res. 2012;470:1932-40.

28. Acker A, Fischer JF, Aminian K, Lécureux E, Jolles BM. Total hip arthroplasty using a cementless dual-mobility cup provides increased stability and favorable gait parameters at five years follow-up. Orthop Traumatol Surg Res. 2017:103:21-5.

29. Adam P, Farizon F, Fessy MH. Dual mobility retentive acetabular liners and wear: surface analysis of 40 retrieved polyethylene implants. Orthop Traumatol Surg Res. 2014;100:85-91.

30. Boyer B, Neri T, Geringer J, Di lorio A, Philippot R, Farizon F. Long-term wear of dual mobility total hip replacement cups: explant study. Int Orthop. 2018;42:41-7.

31. Assaf A, Manara JR, Teoh KH, Evans AR. Mid-term clinical results of the cementless R3 cup and Polarstem total hip arthroplasty. Eur J Orthop Surg Traumatol. 2019;29:827-33

32. Lee PY, Evans AR. Early failure of the Polarstem total hip arthroplasty--can the Australian NJR tell us the full story? J Arthroplast. 2014;29:609-11.

33. 14th Annual Report of the National Joint Registry for England, Wales, Northern Ireland, and the Isle of Man (2017). vol 14th. National Joint Registry for England, Wales, Northern Ireland, and the Isle of Man.

34. Annual Report of the Australian Orthopaedic Association National Joint Replacement Registry (2016). Australian Orthopaedic Association.

35. Seventeen Year Report from the New Zealand Joint Registry (2016).

36. Carlson SW, Liu SS, Callaghan JJ. Not all cementless femoral stems are created equal but the results may be comparable. Bone Joint J. 2017;99-B(1 Supple A):14-7.

37. Molli RG, Lombardi AV Jr, Berend KR, Adams JB, Sneller MA. A short tapered stem reduces intraoperative complications in primary total hip arthroplasty. Clin Orthop Relat Res. 2012;470:450-61.
38. Jacquel A, Le Viguelloux A, Valluy J, Saffarini M, Bonin N. A shortened uncemented stem offers comparable positioning and increased metaphyseal fill compared to a standard uncemented stem. J Exp Orthop. 2019;6:28.

39. Yu H, Liu H, Jia M, Hu Y, Zhang Y. A comparison of a short versus a conventional femoral cementless stem in total hip arthroplasty in patients 70 years and older. J Orthop Surg Res. 2016;11:33.

40. Epinette JA, Manley MT. Uncemented stems in hip replacement-hydroxyapatite or plain porous: does it matter? Based on a prospective study of HA Omnifit stems at 15years minimum follow-up. Hip Int. 2008;18:69-74.

41. Lee GY, Srivastava A, D'Lima DD, Pulido PA, Colwell CWJ. Hydroxyapatitecoated femoral stem survivorship at 10 years. J Arthroplast. 2005;20(7 Suppl 3):57-62.

42. Moed BR, Yu PH, Gruson Kl. Functional outcomes of acetabular fractures. J Bone Joint Surg Am. 2003:85-A:1879-83.

43. Ovre S, Sandvik L, Madsen JE, Roise O. Comparison of distribution, agreement and correlation between the original and modified merle d'Aubigne-Postel score and the Harris hip score after acetabular fracture treatment: moderate agreement, high ceiling effect and excellent correlation in 450 patients. Acta Orthop. 2005;76:796-802.

44. Rice J, Kaliszer M, Dolan M, Cox M, Khan H, McElwain JP. Comparison between clinical and radiologic outcome measures after reconstruction of acetabular fractures. J Orthop Trauma. 2002;16:82-6.

\section{Publisher's Note}

Springer Nature remains neutral with regard to jurisdictional claims in published maps and institutional affiliations.
Ready to submit your research? Choose BMC and benefit from:

- fast, convenient online submission

- thorough peer review by experienced researchers in your field

- rapid publication on acceptance

- support for research data, including large and complex data types

- gold Open Access which fosters wider collaboration and increased citations

- maximum visibility for your research: over $100 \mathrm{M}$ website views per year

At BMC, research is always in progress.

Learn more biomedcentral.com/submissions 